\title{
Desafios e perspectivas da formação do terapeuta ocupacional no campo da saúde mental
}

\section{Challenges and perspectives on the occupational therapist formation in mental area field}

\author{
Sarah Raquel Almeida Lins ${ }^{1}$, Thelma Simões Matsukura ${ }^{2}$
}

http://dx.doi.org/10.11606/issn.2238-6149.v26i3p317-325

Lins SRA, Matsukura TS. Desafios e perspectivas da formação do terapeuta ocupacional no campo da saúde mental. Rev Ter Ocup Univ São Paulo. 2015 set.-dez.;26(3):317-25.

RESUMO: Este estudo objetivou identificar a opinião de docentes de cursos de graduação em Terapia Ocupacional acerca dos desafios e perspectivas implicados na formação acadêmica do terapeuta ocupacional no campo da saúde mental. Trata-se de estudo qualitativo realizado com 14 docentes de saúde mental vinculados a 10 cursos de graduação em Terapia Ocupacional do Estado de São Paulo. A coleta dos dados se deu através de Formulário de Identificação do Participante e de Roteiro de entrevistas semiestruturado que foram descritos e analisados através da identificação de categorias temáticas. Os principais desafios desta formação revelada pelos docentes envolvem a limitação da grade curricular e a distância existente entre o que preconizam as políticas públicas e a realidade observada no campo. Todos os docentes consideram a pertinência da formação generalista bem como da educação continuada para aquisição de conhecimentos mais específicos. Discute-se sobre os desafios e as potencialidades da formação e da integração ensinoserviço, a continuidade à formação, bem como o engajamento dos docentes na proposição de uma formação mais condizente com a realidade do campo. Considera-se que este estudo acrescenta ao conhecimento da área e contribui para o desenvolvimento de reflexões que contemplem a formação do terapeuta ocupacional em saúde mental.

DESCRITORES: Capacitação/políticas; Terapia ocupacional/ educação; Ocupações em saúde/educação; Saúde mental/educação.
Lins SRA, Matsukura TS. Challenges and perspectives on the occupational therapist formation in mental area field. Rev Ter Ocup Univ São Paulo. 2015 Sept.-Dec.;26(3):317-25.

\begin{abstract}
This study aimed to identify the opinion of teachers of Occupational Therapy undergraduate course about challenges and perspectives involved in the academic education of the occupational therapist in the mental health field. It is a qualitative study with 14 teachers of mental health from ten undergraduate courses in Occupational Therapy in the state of Sao Paulo. Data collection was done through the participant ID form and semi- structured interviews that were described and analyzed through the identification of themes. The main challenges of this major mentioned by the teaching members involve the subjects curriculum limitation and the distance between the public policies and the reality noted in this field. All the teaching members consider important the general formation as well as the continuing education in order to learn more specific knowledge. The challenges are discussed and also the graduation potential and the integration between learning and service, the continuing education as well as the professors commitment of offering a program closer to the field's reality. This study contributes to the area development and to development of reflexions about occupational therapist formation in mental health.
\end{abstract}

KEY-WORDS: Training; Occupational therapy/education; Health occupations/education; Mental health/education.

Os resultados apresentados neste artigo são parte integrante da dissertação intitulada "Formação acadêmica do terapeuta ocupacional no campo da saúde mental", desenvolvida por Sarah Raquel Almeida Lins, orientada pela Dra. Thelma Simões Matsukura, elaborada junto ao Programa de Pós-Graduação em Terapia Ocupacional da Universidade Federal de São Carlos. O estudo completo foi parcialmente financiado pela Coordenação de Aperfeiçoamento de Pessoal de Nível Superior - CAPES.

1. Doutoranda do Programa de Pós Graduação em Educação Especial (UFSCar) e Mestre em Terapia Ocupacional pelo Programa de PósGraduação em Terapia Ocupacional da Universidade Federal de São Carlos (UFSCar).

2. Doutora em Saúde Mental pela Universidade de São Paulo. Professora Titular do Departamento de Terapia Ocupacional e dos Programas de Pós-Graduação em Terapia Ocupacional e em Educação Especial da Universidade Federal de São Carlos (UFSCar).

Endereço para correspondência: Sarah Raquel Almeida Lins. Laboratório de Saúde Mental do Departamento de Terapia Ocupacional da UFSCar, Rodovia Washington Luiz, KM 235, Caixa Postal 676, CEP: 13565-905, São Carlos, SP, Brasil. E-mail: sarahlinsto@gmail.com. 


\section{INTRODUÇÃO}

$\mathrm{U}$

ma das dimensões presente nas Diretrizes Curriculares Nacionais dos cursos de graduação em Terapia Ocupacional

(DCN-TO) aponta que as práticas terapêuticas devem ocorrer gradativamente ao longo da graduação, em nível de complexidade crescente, e, também, abranger todas as áreas da Terapia Ocupacional (TO) previstas no currículo ${ }^{1,2}$.

Além de ressaltar, no Parágrafo Único, que “[...] a formação do terapeuta ocupacional deverá atender ao sistema de saúde vigente no país, a atenção integral da saúde no sistema regionalizado e hierarquizado de referência e contrarreferência e o trabalho em equipe" ${ }^{\text {". }}$.

No que se refere ao campo da saúde mental, foco deste estudo, Mângia et al. ${ }^{3}$, realizaram estudo a fim de conhecer e analisar a inserção de egressos em serviços de saúde mental no Sistema Único de Saúde (SUS) bem como as exigências da prática. $\mathrm{O}$ estudo, que envolveu a participação de oito egressos que atuavam no campo da saúde mental, revelou relatos sobre lacunas na formação dos profissionais que consideraram insuficiente $o$ repertório trazido da graduação, sendo necessária a busca por cursos de aprimoramento para melhorar a prática. As autoras destacaram que as competências exigidas pela prática neste novo cenário da saúde mental ainda não são oferecidas na graduação.

Gozzi ${ }^{4}$ realizou estudo que abordou a rede de saúde mental do SUS e a inserção dos terapeutas ocupacionais nos equipamentos que a compõem (CAPS, NASF, UBS, ambulatório, Hospital Psiquiátrico). Os resultados apontaram que os 13 terapeutas ocupacionais participantes que ingressaram nessas redes referem lacunas na graduação afirmando que tiveram mais teoria do que prática o que dificultou a atuação profissional após a formação acadêmica e, consequentemente, gerou o desconhecimento relacionado às diretrizes do seu trabalho, ficando, muitas vezes, com poucos ou sem instrumentos que apoiassem e direcionassem o desenvolvimento de suas práticas.

A autora discute ainda que, apesar de haver uma variedade de equipamentos e de propostas direcionados à saúde mental, do terapeuta ocupacional ser um profissional ativo neste campo, e da existência de uma importante preocupação das instituições formadoras com a inserção curricular das políticas públicas de saúde nas áreas estudadas, há ainda desconhecimento a respeito das políticas públicas em saúde mental pelos profissionais, inclusive entre os que são recém-formados que, aparentemente, participaram de arranjos curriculares mais recentes ${ }^{4}$.

Em relação à TO no campo da saúde mental infantil, Bueno ${ }^{5}$ identificou, a partir da ótica de 24 terapeutas ocupacionais inseridos em 18 unidades de CAPSi do Estado de São Paulo, que existem lacunas na formação teórica (conteúdo insuficiente das disciplinas básicas/clínica e de TO) e prática (ausência de prática/estágio/contato direto) do terapeuta ocupacional para o atendimento desta população, dentre outras.

A literatura internacional também apresenta questões em relação à formação do terapeuta ocupacional em saúde mental que são similares às apresentadas pelos estudos realizados no Brasil como, por exemplo, as mudanças no contexto da atenção em saúde mental que trouxeram novas demandas para o campo e exigiram maior qualificação dos profissionais, em direção ao atendimento comunitário, à desinstitucionalização, à gestão dos serviços, levando as instituições formadoras a buscar alternativas político-pedagógicas mais adequadas ao novo cenário ${ }^{6,7}$

No Chile, Rueda e Soto ${ }^{6}$, ao realizar a avaliação de uma disciplina relacionada à saúde mental, que fazia parte da grade curricular do curso de TO da Universidade do Chile, ressaltou que a mudança no contexto da atenção em saúde mental que passou de 'reclusão psiquiátrica' que limitava as potencialidades e a autonomia do indivíduo, para a 'liberdade humana' onde o indivíduo tem a possibilidade de ações, de tomada de decisões e atos voluntários foi a base para a proposição de novas estratégias de práticas. Tais estratégias envolviam a atuação dos estudantes como facilitadores da socialização no ambiente hospitalar e no fomento de experiências que promovessem autonomia nos ambientes socioculturais para promoção da cidadania.

No Reino Unido, Banningan et al. ${ }^{7}$, debatendo sobre o currículo de TO, sugerem que a formação do terapeuta ocupacional inclua parte de formação base e parte de formação especialista, a fim de que o profissional esteja mais preparado para atender as exigências dos novos serviços de saúde mental, pois com as mudanças nas legislações, houve a inclusão de práticas que não tem sido contempladas na graduação como, por exemplo, a atenção junto à população com demência, serviços de crianças e adolescentes, atenção primária, doenças mentais leves, moderadas e severas, saúde mental da mulher.

Gutman $^{8}$ considera que para contemplar as políticas públicas de saúde e as complexidades da pessoa com transtorno mental é necessário dar continuidade à revisão, exploração e investigação da prática da $\mathrm{TO}$ em saúde mental para torná-las, de fato, efetivas.

González e Almeida ${ }^{9}$ discorrem que a assistência à saúde, de um modo geral, deve atender ao sistema de saúde vigente no país. Para isso, as instituições formadoras 
vêm sendo pressionadas por mudanças no processo de formação e na maneira como a universidade se relaciona com a sociedade. Este desafio deve lograr a formação de profissionais sensíveis aos aspectos da integralidade nas práticas realizadas em saúde.

Alguns Projetos Político-Pedagógicos (PPP) de cursos de graduação em Terapia Ocupacional de diversas instituições do país indicam que, para que o perfil definido nas diretrizes curriculares seja atingido, a formação deve estar voltada para experiências na área de saúde pública. Além disso, diversos cursos oferecem disciplinas teóricas e práticas com estágios no campo da saúde mental ${ }^{10,11,12}$.

Assim, apesar de haver conteúdos teóricos e práticos já previstos nas diretrizes curriculares e, possivelmente, em cada projeto pedagógico dos cursos de graduação que são oferecidos aos discentes da graduação em TO, parece haver uma lacuna entre o que está previsto para a formação no campo da saúde mental e a efetivação da mesma nos diferentes equipamentos de saúde mental que o profissional terapeuta ocupacional se insere ${ }^{4,5}$.

Este trabalho se debruça sobre a formação do terapeuta ocupacional em saúde mental através da identificação da opinião de docentes de cursos de graduação em Terapia Ocupacional acerca dos desafios e perspectivas implicados nesta formação, considerando as políticas públicas de saúde e as DCN-TO.

\section{PROCEDIMENTOS METODOLÓGICOS}

Trata-se de estudo atrelado à pesquisa mais ampla (o estudo foi submetido ao Comitê de Ética em Pesquisa em Seres Humanos da Universidade Federal de São Carlos - UFSCar e aprovado sob o Parecer $n^{\circ}$ 321.653) do tipo transversal, descritivo de abordagem qualitativa ${ }^{13}$.

Foram participantes do estudo 14 docentes do campo da saúde mental, vinculados a cursos de graduação em Terapia Ocupacional do estado de São Paulo.

Os critérios de inclusão utilizados no estudo foram: cursos de graduação em Terapia ocupacional reconhecidos pelo MEC, com, pelo menos, cinco anos de funcionamento e com turmas de último ano ativas, bem como docentes de disciplinas relacionadas à saúde mental com, pelo menos, um ano de experiência no campo, sendo que todos, instituições e docentes, também deveriam aceitar participar do estudo.

Para a coleta de dados utilizou-se de um Formulário de Identificação do Participante e de um Roteiro de entrevistas semiestruturado, ambos elaborados pelos autores a partir de revisão de literatura e submetido à avaliação de especialistas e pesquisadores na área. O roteiro de entrevistas, composto por questões abertas, versava sobre os desafios da formação em saúde mental, os aspectos satisfatórios e problemáticos do ensino teórico-prático neste campo, a articulação com as políticas públicas, dentre outros.

Para localização dos participantes, foram convidados a participar da pesquisa todos os 14 dos 22 cursos de graduação em Terapia Ocupacional do Estado de São Paulo registrados no INEP (até 22/08/2013 havia 22 cursos de TO em atividade no Estado de São Paulo), que respondiam aos critérios estabelecidos para esta pesquisa. Destes, 10 coordenadores consentiram com a participação (5 de natureza pública e 5 de natureza privada) e concederam nomes e e-mails dos docentes que respondiam aos critérios de participação.

Após o aceite para participação, a entrevista com os docentes foi realizada conforme data, horário, local e forma (presencial ou por videoconferência) definidos pelos mesmos, que na ocasião da entrevista entregaram o Termo de Consentimento assinado e autorizaram a gravação das entrevistas em áudio.

Os dados foram organizados em planilhas no Microsoft Excel e analisados por meio da análise temática através da identificação de categorias ${ }^{14}$.

\section{RESULTADOS}

\section{Caracterização dos participantes}

Do total de 24 docentes indicados 14 efetivaram a participação (dois recusaram o convite, cinco não deram retorno e três não efetivaram a participação devido à ausência de horário livre, descredenciamento da IES de vínculo e solicitação de retirada da pesquisa). Destes, 11 apontaram que atuam na docência em saúde mental desde $o$ início da atividade docente, que variou entre um e 29 anos, apenas uma docente optou por não responder este item por considerar a dificuldade em mensurar o quanto de saúde mental havia em sua carreira docente. Todos realizaram formação pós-graduada, a maioria (13) em nível stricto sensu (nove doutores e quatro mestres).

\section{Resultados das entrevistas realizadas junto aos docentes}

Os participantes docentes foram identificados pela letra D de forma enumerada.

Os resultados advindos das entrevistas resultaram na identificação de cinco categorias que são apresentadas na Figura 1. 


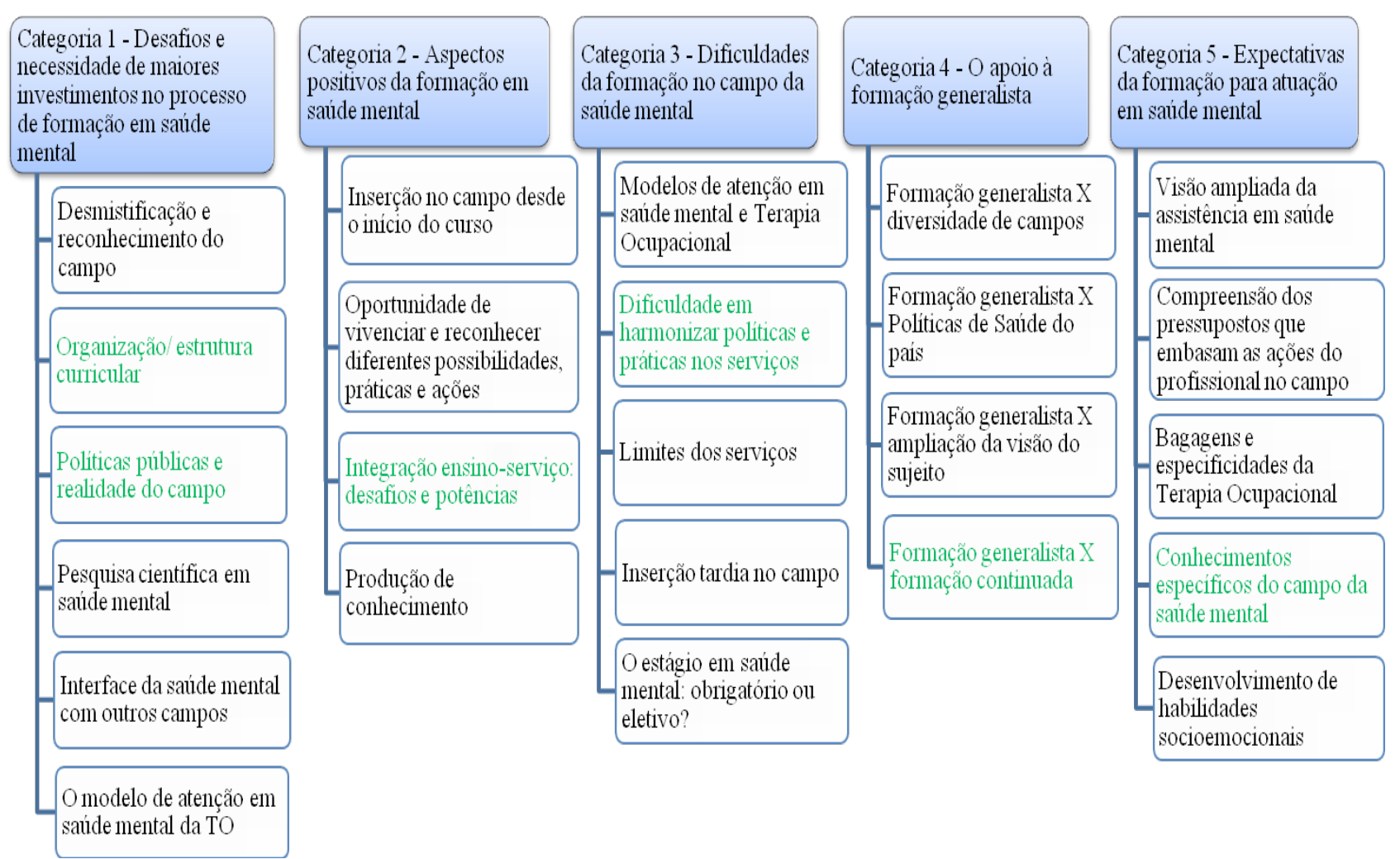

Figura 1 - Categorias e temas dos resultados das entrevistas com os docentes

Neste artigo, serão apresentados os resultados e posteriormente discutidos alguns dos temas vinculados a cada uma das cinco categorias identificadas. Assim, serão focalizados a seguir os seguintes temas, conforme Figura 2.

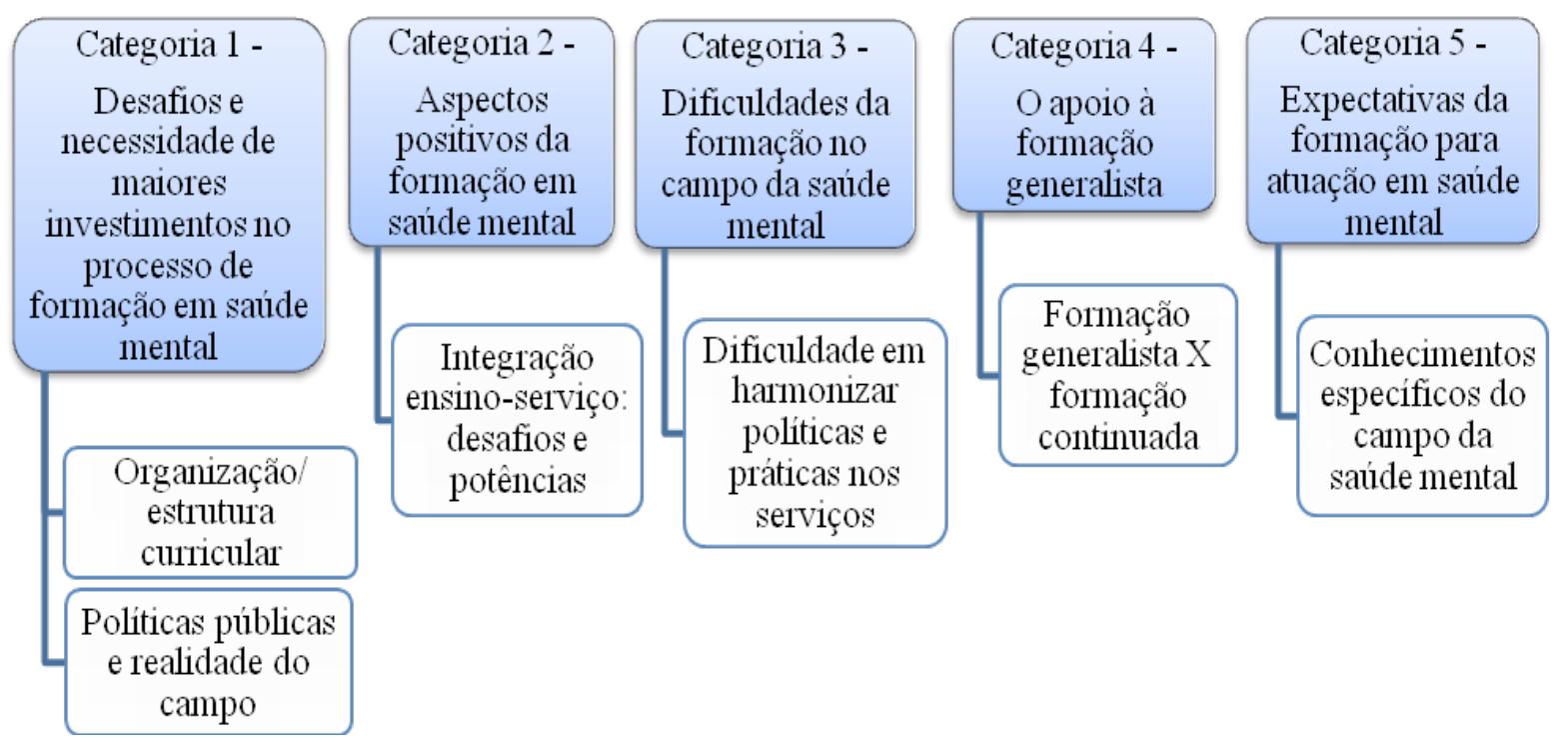

Figura 2 - Categorias e temas dos resultados das entrevistas com os docentes discutidos neste estudo 


\section{Categoria 1: Desafios e necessidade de maiores investimentos no processo de formação em saúde mental}

\section{Tema: Organização/ estrutura curricular}

Os docentes consideram que um dos principais desafios para a formação em saúde mental refere-se ao elenco e organização dos conteúdos que devem compor a formação em saúde mental dentro do tempo estipulado pela grade curricular do curso, como nos apresenta o relato a seguir.

[...] eu acho que é, dentro de um curso de graduação, você encontrar espaço e tempo para abordar os aspectos mais relevantes do campo da saúde mental e também articulando e relacionando isso com as politicas atuais de saúde mental que tem uma dinâmica, que sempre tem mudanças [...] (D6)

Além destes desafios, os docentes consideram que a inserção do discente no campo de práticas ocorre mais tardiamente. Conforme ilustra o relato que segue.

[...] Eu acho que o aluno demora a ter contato com o conteúdo de saúde mental, tanto teórico quanto prático. No terceiro ano eles têm um pouco de contato com a saúde mental, com um caráter mais de promoção da saúde mental, ainda não com o paciente já diagnosticado que ele só vai ter no estágio no último ano. (D2)

Tema: Políticas públicas e realidade do campo

$\mathrm{O}$ presente estudo também identificou que os docentes identificam como desafios para a formação do terapeuta ocupacional no campo da saúde mental a necessidade de maior compreensão das políticas públicas de saúde mental além do desafio da concretização dos pressupostos da reabilitação psicossocial, como revelam os trechos dos relatos dos docentes.

[...] existe uma dimensão que precisa ser desenvolvida que é uma postura política, senão a gente faz só meio caminho, quer dizer, se o aluno não tem clareza sobre as políticas públicas de saúde e de saúde mental que norteiam as práticas em saúde mental, inclusive a do terapeuta ocupacional, ele muitas vezes vai acabar reproduzindo modelos de intervenção que já não tem mais lugar aqui [...]. (D8)

\section{$\checkmark$ Categoria 2: Aspectos positivos da formação em saúde mental}

Tema: Integração ensino-serviço: desafios e potências

Os docentes também apontaram aspectos positivos da formação em saúde mental bem como as dificuldades desta formação. Como aspectos positivos da formação em saúde mental os docentes enfatizaram os desafios e potências que envolvem a integração ensino-serviço, de acordo com o seguinte relato.

[...] estar vivenciando os desafios e as coisas boas, os desafios, as contradições dos serviços, em especial dos serviços territoriais, por que todos os estágios no nosso caso são nos serviços construídos a partir da Reforma Psiquiátrica, então são basicamente em CAPS, seja na área da infância, do sofrimento psíquico grave ou álcool e drogas, então de satisfatório tem essa possibilidade de exercitar esse encontro com os usuários e com a realidade dos serviços [...]. (D11)

\section{$\checkmark$ Categoria 3: Dificuldades da formação no campo da saúde mental}

Tema: Dificuldade em harmonizar políticas e práticas nos serviços

Por outro lado, os participantes destacaram a dificuldade em conciliar as políticas e as práticas nos serviços, além de abordar a existência de limites nos serviços como, por exemplo, equipes que ainda não atuam de forma integrada, como indica o seguinte relato.

Tem alguns lugares [...] onde a gente faz as práticas de estágio, o discurso da equipe é remissão de sintomas [...], então não se pensa discussão de caso, Projeto Terapêutico Singular, visita domiciliar, atendimento familiar, então todas as situações acabam ficando prejudicadas e eu acredito que isto seja um problema, mas aí [...] eu trouxe aí uma questão da direção, se quem está acima pensa numa relação de horizontalidade, pensa num projeto terapêutico singular que são ações da saúde mental que a gente traz [...], eu acredito que é possivel rever alguns elementos da saúde mental para poder melhorar o trabalho [...]. (D5)

\section{$\checkmark$ Categoria 4: $O$ apoio à formação generalista} continuada

Tema: Formação generalista X formação

Outro aspecto relevante apontado pelos docentes refere-se ao apoio à formação generalista, que é prevista pelas DCN-TO. Todos os participantes concordaram que 
esta é a estratégia mais adequada para a formação do terapeuta ocupacional que recebe a formação necessária para atuação nas mais diversas áreas de práticas, dando continuidade à formação por meio de cursos e programas de aprimoramento profissional, como pode ser verificado por meio dos relatos que seguem.

Eu concordo totalmente, acho que a graduação é um espaço para formar um profissional aberto, que acho que as especificidades vêm depois, na formação continuada, nos interesses, nos encontros com o mundo com as necessidades profissionais, do território onde essa pessoa vai fazer a sua contribuição acho que isso tem que vir depois. Acho que a graduação tem que fazer essa formação generalista, é um compromisso éticopolítico. (D10)

\section{$\checkmark$ Categoria 5: Expectativas da formação para atuação no campo da saúde mental}

mental

\section{Tema: Visão ampliada da assistência em saúde}

Os resultados das entrevistas com os docentes também relevaram a expectativa dos participantes em relação à formação esperada para atuação no campo da saúde mental. Os relatos a seguir apontam que espera-se que a formação inclua tanto o conteúdo teórico e prático específico da saúde mental quanto a articulação destes com outros campos bem como com outros aspectos do indivíduo, para garantir a integralidade da assistência em saúde preconizada pelas políticas públicas.

Acho que ele também deve ser capaz de ser [...] um agente tanto facilitador como transformador e até mesmo integrador do sujeito do cuidado, para com os aspectos sociais dele, para com a sociedade mesmo, porque assim ele consegue atuar de forma a garantir a integralidade da assistência a esse indivíduo e seria basicamente isso. (D12)

\section{DISCUSSÃO}

Os resultados focalizados neste estudo indicam que um dos principais desafios para a formação em saúde mental apontado pelos docentes refere-se ao reconhecimento da existência de um vasto conteúdo considerado importante para a formação neste campo, ao passo em que há o desafio da abordagem dos principais conteúdos dentro do tempo e espaço estipulado na grade curricular do curso.

Considera-se que a formação em saúde mental demanda por maior aprofundamento em conteúdos relacionados às políticas públicas de saúde mental, incluindo os princípios e diretrizes do SUS, redes de serviços, programas de saúde voltados para a população alvo da saúde mental (infanto-juvenil, álcool e drogas, dentre outros), integralidade e gestão, que são considerados norteadores a prática profissional neste campo ${ }^{3}$.

Nesta direção, cabe refletir no sentido de compreender quais seriam os conteúdos fundamentais para garantir uma formação mais propositiva que atenda às demandas da prática e que também garanta a perspectiva de ações visando a implementação das políticas públicas do campo.

As DCN-TO preconizam que a formação deve conter experiências práticas desde o início da graduação, gradativamente, com complexidade crescente ${ }^{2}$.

Os resultados deste estudo revelaram que a inserção do discente no campo de práticas em saúde mental tem ocorrido mais tardiamente, apesar dos docentes considerarem de fundamental importância a antecipação desta estratégia.

Este desafio também está presente na formação do TO em saúde mental em outros países como a Austrália, onde foi realizado um estudo que envolveu a participação de 19 discentes do primeiro ano do curso e que revelou que o contato com a prática em saúde mental no início do curso proporciona maior compreensão em relação às pessoas com doença mental, além de desenvolver e aperfeiçoar habilidades de resolução de problemas ${ }^{15}$.

A literatura reforça tais considerações uma vez que o contato do discente com a prática em saúde mental desde o início da formação, incluindo a realização de discussões e reflexões sobre esta prática, dentre outras atividades, configuram uma poderosa forma para preparar os discentes para atender as demandas do campo ${ }^{15,16}$.

Como estratégia para antecipar a realização das práticas, os docentes sugerem o envolvimento em atividades complementares que, como são opcionais, implica que tal efetivação depende do interesse do discente e de possibilidades oferecidas institucionalmente.

Ademais, se coloca o desafio e a necessidade de reflexão acerca de possibilidades de inserção no campo da saúde mental em períodos mais precoces, tanto no que se refere à maturidade dos discentes (idade, experiências de vida, dentre outras), como no que tange à entrada em um campo complexo que é mais um dentre outros campos que compõe a área da Terapia Ocupacional.

Ainda considerando os desafios presentes na formação discente, verificou-se neste estudo que os docentes expressaram sobre a discrepância entre o que ensinam e preconizam as políticas, e a prática existente nos serviços. 
Tais considerações envolvem, dentre outros, a concepção adotada nos serviços e a dificuldade de integração entre os profissionais e as equipes.

Neste sentido, estudos recentes apontam dificuldades ou ausência de mudanças no que se refere à efetivação das políticas públicas de saúde mental, incluindo ações de matriciamento, de saúde mental na atenção básica bem como a construção de serviços substitutivos ao hospital desenvolvidos no contexto da comunidade ${ }^{3,17,18,19}$.

Esse encontro entre o discente que está em fase de aprendizado e o serviço que, muitas vezes, contrapõe a política de saúde mental, que é cheio de divergências, pode ser uma oportunidade de proporcionar enriquecimento à formação caso haja desenvolvimento de ações propositivas por parte do discente, uma vez que a confrontação destas dificuldades pode lograr uma formação mais integrada e coerente com a realidade dos usuários do SUS ${ }^{21}$.

Neste contexto, destaca-se aqui a potencialidade que pode ser explorada a partir das parcerias ensino-serviço, que normalmente acontecem com a realização de estágios e práticas supervisionadas ${ }^{21}$.

Considerando a integração ensino-serviço como um espaço privilegiado de ensino e formação do profissional da saúde, é fundamental que os trabalhadores dos serviços estejam em sintonia com as novas propostas de transformação da assistência em saúde ${ }^{22}$. Estudos futuros devem contribuir para o aprofundamento e compreensão desta temática.

Neste estudo, a integração ensino-serviço foi apresentada como uma potência para a formação no sentido de que a possibilidade de vivenciar os desafios e contradições dos serviços proporciona maior exercício da prática, mas também como um desafio devido à carência de recursos e à dificuldade em estabelecer parcerias entre IES e serviços.

A literatura sugere maior atenção e planejamento no processo de integração ensino-serviço devido ao atual contexto da assistência em saúde que demanda integração entre as equipes, bem como atenção individual e coletiva aos usuários ${ }^{22}$, e, também, para que o discente sinta-se familiarizado com a dinâmica dos serviços, e compromissado com as políticas e com as ações a serem desenvolvidas, tornando-o capaz de ser um agente transformador das práticas nos serviços ${ }^{23}$.

Nesta direção, este estudo revelou que a estratégia da integração ensino-serviço precisa ser ampliada e mais presente na formação do terapeuta ocupacional, para isso considera-se a demanda por um docente que contribua na busca de soluções que atendam as prioridades assistenciais do território, do SUS ou mesmo da política.
Além das parcerias e da formação em serviço, compreende-se que os resultados deste estudo revelam também como desafio da formação neste campo capacitar os discentes (futuros profissionais) para enfrentarem tal discrepância no sentido da transformação e avanço dos serviços. Compreende-se que esta dimensão está colocada tanto para a TO como também para outras especialidades envolvidas neste campo.

Importa problematizar sobre como avançar neste processo de capacitação, efetivamente formando um discente ativo, transformador, crítico, com domínio conceitual e prático; e, ao mesmo tempo, acrescentar a esta formação uma dimensão que implica posicionamentos na própria prática em um contexto contraditório que é repleto de avanços, mas com muitas dificuldades e obstáculos a serem ultrapassados. Assim, tem-se concordância com as considerações de Constantinidis e Cunha ${ }^{20}$ que destacam como desafio da formação do terapeuta ocupacional o preparo para equacionar as questões relacionadas às condições ideais e reais que compõem a rotina dos serviços, que inclui o empenho na transformação da assistência em saúde, conforme as demandas apresentadas pela população.

No entanto, fica claro também que muito está demandado para além da formação dos profissionais desse campo e, aponta-se que tanto as políticas do setor como os meios para viabilizá-las são ações fundamentais e também de responsabilização da esfera da gestão em diferentes níveis.

Outro importante aspecto apontado pelos docentes refere-se a concordância, unânime, relativa a compreensão de que a formação generalista é a mais adequada para este tipo de formação.

Drummond e Rodrigues ${ }^{24}$ apontam que a formação generalista tem o objetivo de formar profissionais que atendam as dinâmicas e diversidades do contexto da saúde brasileira. As autoras concordam que a formação profissional deve ser contínua e apoiam a realização de programas de aprimoramento para melhorar a atuação profissional ${ }^{24}$. Os resultados deste estudo reforçam tais considerações, sendo que os docentes vinculam a formação continuada como uma forma de aprimorar e aprofundar conhecimentos específicos da prática como, por exemplo, através da realização de programas de aprimoramento, especialização, dentre outros.

Considerando que a formação generalista propõe um conhecimento mais geral sobre a profissão e, sob esta perspectiva, os conhecimentos mais específicos de um determinado campo passam a compor os conteúdos gerais, ou então integram as atividades complementares dos $\operatorname{cursos}^{25}$, tem-se que as atividades complementares bem como a continuidade à formação configuram-se como 
estratégias que, aliada à grade curricular, possibilita o aprofundamento ou expansão de conteúdos específicos.

Desse modo, apesar dos desafios e das perspectivas para a formação em saúde mental apresentados neste estudo através dos relatos dos participantes, a formação em saúde mental foi avaliada positivamente pelos mesmos. Tal resultado corrobora com a assertiva que compreende que os investimentos colocados para a formação do TO em saúde mental tem apresentado resultados positivos, e que o terapeuta ocupacional tem se engajado no desenvolvimento de práticas voltadas para a efetivação da proposta da reabilitação psicossocial $1^{4,5,6,26}$.

Entretanto, os resultados também evidenciam que muito está demandado para a formação graduada e para além dela, sendo necessária a viabilização de ações que consolidem os pressupostos da política a fim de lograr uma formação que, de fato, atenda as necessidades dos usuários dos serviços.

\section{CONCLUSÕES}

Este estudo objetivou identificar a opinião de docentes de cursos de graduação em TO acerca dos desafios e perspectivas implicados na formação acadêmica do terapeuta ocupacional no campo da saúde mental, através

\section{REFERÊNCIAS}

1. Brasil. Ministério da Educação e Cultura. Padrão mínimo de qualidade para os cursos de Terapia Ocupacional, 1997. Brasília; 1997. Disponível em: http://portal.mec.gov.br/sesu/ arquivos/pdf/pad_qua.pdf.

2. Brasil. Ministério da Educação e Cultura. Parecer CNE/CES 6/2002. Brasília: Conselho Nacional de Educação; 2002 [citado set. 2014]. Disponível em: http://portal.mec.gov.br/ cne /arquivos/pdf/CES062002.pdf.

3. Mângia EF, Muramoto MT, Marques ALM. Formação profissional e serviços de saúde mental no SUS: estudo sobre a inserção de egressos do Curso de Terapia Ocupacional da FMUSP. Rev Ter Ocup Univ São Paulo. 2010;21(2):14857. Disponível em: http://www.revistas.usp.br/rto/article/ viewFile/14098/15916.

4. Gozzi APNF. O processo de trabalho do terapeuta ocupacional na rede de saúde mental: focalizando a avaliação inicial do qual foi possível aprofundar dimensões presentes na formação acadêmica no campo da saúde mental dentro da formação do profissional, bem como os principais desafios, limites e potencialidades desta formação, considerando as políticas públicas e as DCN-TO.

A partir dos resultados discutiu-se questões para estudos futuros e outras que podem balizar debates e reflexões, dentre elas, destaca-se as relativas à implementação de práticas no campo da saúde mental em momentos mais iniciais do curso, a parceria e práticas ensino-serviço, a relevância da formação generalista para a formação do terapeuta ocupacional, e o que se espera dessa formação.

Verificou-se que os desafios e perspectivas presentes na formação graduada do terapeuta ocupacional em saúde mental apontados pelos docentes são demandas e potencialidades que podem contribuir para o amadurecimento profissional dos discentes, considerando a importância da vivência no contexto dinâmico e discrepante da realidade do campo, e que esforços têm sido envidados para que esta formação seja tratada como um elemento impulsionador e realizador das propostas do SUS, por meio da criação de condições para a transformação da prática nos serviços.

Considera-se que este estudo forneceu evidências que podem subsidiar a realização de estudos futuros que produzam novas reflexões sobre a formação do terapeuta ocupacional em saúde mental.

[Dissertação]. São Carlos: Universidade Federal de São Carlos; 2013. Disponível em: http://www.bdtd.ufscar.br/htdocs/ tedeSimplificado/tde_busca/arquivo.php? $\operatorname{codArquivo}=5815$.

5. Bueno AR. Terapia Ocupacional no campo da saúde mental infanto-juvenil: revelando as ações junto aos Centros de Atenção Psicossocial Infanto-juvenil (CAPSi) [Dissertação]. São Carlos: Universidade Federal de São Carlos; 2013. Disponível em: http://www.bdtd.ufscar.br/htdocs/ tedeSimplificado/tde_busca/arquivo.php? codArquivo=6085.

6. Rueda L, Soto P. Terapia Ocupacional en psiquiatría y salud mental: formación en pregrado. Rev Chilena Ter Ocup. 2011;1:10-3. doi: 10.5354/0717-5346.2001.117.

7. Banningan $\mathrm{K}$, Lewis $\mathrm{P}$, Laver-Fawcett A, Wolverson C, Long C, Cadman D, Cotteril D. It is time for a mental health pathway in undergraduate programmers? Br J Occup Ther. 2011;74(3):1536. doi: 10.4276/030802211X12996065859409. 
8. Gutman, SA. Special Issue: effectiveness of occupational therapy services in mental health practice. Am J Occup Ther. 2011;65(3):235-7. doi:10.5014/ajot.2011.001339

9. Gonzalez AD, Almeida RJ. Integralidade da saúde - norteando mudanças na graduação dos novos profissionais. Ciên Saúde Coletiva. 2010;15(3):757-62.

10. Universidade Federal de São Carlos (UFSCar). Projeto Pedagógico do Curso de Terapia Ocupacional. São Carlos; 2007 [citado jul. 2015]. Disponível em: http://www.dto.ufscar. br/projeto-pedagogico-to.

11. Universidade Federal do Espírito Santo (UFES). Projeto Pedagógico do Curso de Terapia Ocupacional. Vitória; 2007 [citado jul. 2015]. Disponível em: http://www. terapiaocupacional.ufes.br/projeto-pedagogico.

12. Instituto Federal do Rio de Janeiro (IFRJ) Realengo. Projeto Pedagógico do Curso de Terapia Ocupacional. Rio de Janeiro; 2012 [citado jul. 2015]. Disponível em: http://www.ifrj.edu. br/webfm_send/3509.

13. Sampieri RH, Collado CF, Lúcio PB. Metodologia de pesquisa. 3a ed. São Paulo: McGrab-Hill; 2006.

14. Bardin L. Análise de conteúdo. Lisboa: Edições 70; 1977.

15. Beltran RO, Scanlan JN, Hancock N, Luckett T. The effect of first year mental health fieldwork on attitudes of occupational therapy students towards people with mental illness. Aust Occup Ther J. 2007;54:42-8. doi: 10.1111/j.14401630.2006.00619.x.

16. Almeida MM, Morais RP, Guimarães DF, Machado MFAS, Diniz RCM, Soares Nuto AS. Da teoria à prática da interdisciplinaridade: a experiência do Pró-Saúde Unifor e seus nove cursos de graduação. Rev Bras Educ Med. 2012;36(1):119-26. http://dx.doi.org/10.1590/S010055022012000200016 .

17. Cavalheiro MTP, Guimarães AL. Formação para o SUS e os desafios da integração ensino-serviço. Cad FNEPAS. 2011;1:19-27. Disponível em: http://www.sbfa.org.br/fnepas/ artigos_caderno/v11/artigo2_formacao_para_sus.pdf.
18. Mângia EF, Muramoto MT. Modelo de Matriz: ferramenta para a construção de boas práticas em saúde mental comunitária. Rev Ter Ocup Univ São Paulo. 2009;20(2):188-25. http:// dx.doi.org/10.11606/issn.2238-6149.v20i2p118-125.

19. Pinto ATM, Ferreira AAL. Problematizando a reforma psiquiátrica brasileira: a genealogia da reabilitação psicossocial. Psicol Estud (Maringá). 2010;15(1):27-34. http://dx.doi. org/10.1590/S1413-73722010000100004.

20. Constantinidis TC, Cunha AC. A formação em terapia ocupacional entre o ideal e o real. Rev Ter Ocup Univ São Paulo. 2013;24(2):149-54. doi: 10.11606/issn.2238-6149. v24i2p149-154.

21. Pimentel AM, Costa MTB, Souza FR. Terapia Ocupacional na Atenção Básica: a construção de uma prática. Rev Ter Ocup Univ São Paulo. 2011;22(2):110-6. Disponível em: http:// www.revistas.usp.br/rto/article/viewFile/14128/15946.

22. Albuquerque VS, Gomes AP, Rezende CHA, Sampaio MX, Dias OV, Lugarinho RM. A integração ensino-serviço no contexto dos processos de mudança na formação superior dos profissionais da saúde. Rev Bras Educ Med. 2008;32(3):35662. Disponível em: http://www.scielo.br/pdf/rbem/v32n3/ v32n3a10.pdf.

23. Finkler M, Caetano JC, Ramos FRS. Integração ensinoserviço no processo de mudança na formação profissional em Odontologia. Interface (Botucatu). 2011;15(39):1053-67. http://dx.doi.org/10.1590/S1414-32832011005000023.

24. Drummond AF, Rodrigues AMVN. Os desafios da implantação de uma proposta de flexibilização curricular nos cursos de terapia ocupacional. Rev Ter Ocup Univ São Paulo. 2004;15(3):106-11. http://dx.doi.org/10.11606/issn.22386149.v15i3p106-111.

25. Santos, SSC. Perfil do egresso de Curso de Enfermagem nas Diretrizes Curriculares Nacionais: uma aproximação. Rev Bras de Enf. 2006; 59 (2): p. 217-221. http://dx.doi.org/10.1590/ S0034-71672006000200018.

26. Ballarin MLGS, Carvalho FBC. Considerações acerca da Reabilitação Psicossocial: aspectos históricos, perspectivas e experiências. In: Cavalcanti A, Galvão C. Terapia Ocupacional: fundamentação e prática. Rio de Janeiro: Guanabara Koogan; 2007. p.162-70. 